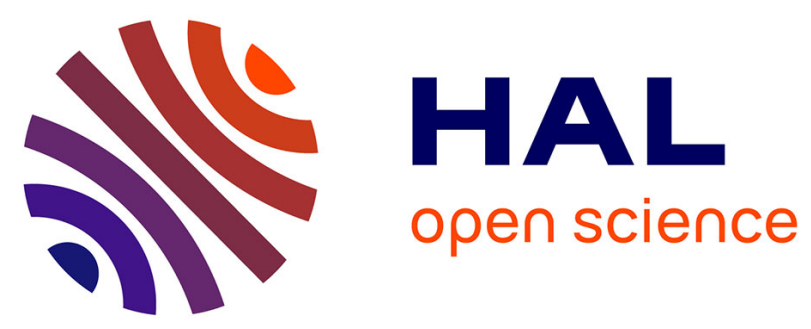

\title{
Colon tumor promotion, is it a selection process? Effects of cholate, phytate, and food restriction in rats on proliferation and apoptosis in normal and aberrant crypts.
}

\author{
Denis E. Corpet, Sylviane Taché, Ginette Peiffer
}

\section{To cite this version:}

Denis E. Corpet, Sylviane Taché, Ginette Peiffer. Colon tumor promotion, is it a selection process? Effects of cholate, phytate, and food restriction in rats on proliferation and apoptosis in normal and aberrant crypts.. Cancer Letters, 1997, 114, pp.135-138. hal-00283712

\section{HAL Id: hal-00283712 \\ https://hal.science/hal-00283712}

Submitted on 10 Jun 2008

HAL is a multi-disciplinary open access archive for the deposit and dissemination of scientific research documents, whether they are published or not. The documents may come from teaching and research institutions in France or abroad, or from public or private research centers.
L'archive ouverte pluridisciplinaire HAL, est destinée au dépôt et à la diffusion de documents scientifiques de niveau recherche, publiés ou non, émanant des établissements d'enseignement et de recherche français ou étrangers, des laboratoires publics ou privés. 


\title{
Colon tumor promotion, is it a selection process? Effects of cholate, phytate, and food restriction in rats on proliferation and apoptosis in normal and aberrant crypts.
}

\author{
Denis E. Corpet ${ }^{*}$, Sylviane Taché, Ginette Peiffer. \\ Ecole Nationale Vétérinaire, Laboratoire de Sécurité des Aliments, Institut National de la Recherche Agronomique, \\ 23 Ch. Capelles, 31076 Toulouse, France.
}

\begin{abstract}
Promotion would suppose the selection of initiated cells. We tested the selection of aberrant crypt cells by cholic acid, a colon cancer promoter, and the effect of protectors, phytate and food restriction. After an azoxymethane injection, rats were allocated to a control diet, or to supplements of cholic acid, sodium phytate, or to a $50 \%$ food restriction. The proliferation and apoptosis of 1200 crypts were assessed, after immuno-staining for BrdU. Cholic acid increased the proliferation of aberrant crypts but not of normal crypts. Phytate and food restriction decreased the proliferation of normal crypts, but not of aberrant crypts. Apoptosis was not affected by diets. Results support the hypothesis that cholic acid can select initiated cells in the colon.
\end{abstract}

Keywords: selection, aberrant crypt foci, cholate, phytate, food restriction.

\section{Introduction}

Cancer promotion would suppose a selection of initiated cells, more resistant to chemical toxicity than normal cells (e.g., in Farber's model of liver carcinogenesis). Reciprocally, the protection afforded by food restriction is related to a counterselection of initiated cells: a decrea-sed proliferation and increased apoptososis (cell death) of liver preneoplastic foci (3). In the colon, putative preneoplastic lesions are aberrant crypt foci (ACF). ACF are specifically induced by colon carcinogens, promoted by promoting diets, inhibited by inhibitors of carcinogenesis. Rodents and humans ACF display mutations and histologic changes observed in colonic tumors. The growth of ACF correlates with the adenocarcinoma yield $(8,15)$.

* Corresponding author. Tel. (33) 6119 3982, Fax (33) 61491263.
Bile salts are putative cancer promoters (12), and dietary cholate can promote colon tumors in rats $(8,11)$. In contrast, dietary phytate (inositol hexaphosphate) consistently decreases colon carcinogenesis $(15,18,21)$. Food (or caloric) restriction also decreases liver and colon carcinogenesis $(3,6,7)$.

We speculated that a colon tumor promoter, cholate, would "select" ACF cells by increasing their relative proliferation, and/or by decreasing their relative apoptosis, compared to cells in normal crypts. We speculated that, reciprocally, protectors like phytate and food restriction, would act in the opposite way, and counterselect the ACF. These hypotheses were tested by comparing the proliferation and apoptosis in normal and aberrant crypts, in rats subjected to food restriction, or to dietary cholate or phytate. 


\section{Materials and Methods}

Twenty-four five-week-old female Sprague Dawley rats (Iffa-Credo, l'Arbresle, France) were housed 2 rats per cage (stainless steel grid floor) at $22^{\circ} \mathrm{C}, 12: 12 \mathrm{~h}$ light-dark cycle, with ad libitum tap water and rodent chow. After 7 days of acclimatization, they were given a single azoxymethane injection to initiate colon cancer $(20 \mathrm{mg} / \mathrm{kg}$ i.p. in $\mathrm{NaCl} 9 \mathrm{~g} / \mathrm{l}$, from Sigma, St.Quentin-F), and fed a semi-purified powdered diet similar to AIN76 (UAR210 containing casein $23 \%$, starch + glucose $58 \%$, fat $5 \%$, cellulose $6 \%$, mineral mix $7 \%$, vitamin mix $1 \%$, from UAR, Villemoisson-F). Seven days later, they were randomly allocated to 4 groups of 6 rats. Group 1 was the control, given ad libitum pure diet and water. Cholic acid $(0.2 \%$, from Sigma) was added to the diet of group 2. Sodium phytate (2\%, from Sigma) was added in the drinking water of group 3, and brought to $\mathrm{pH} 7$ with $\mathrm{HCl} 2 \mathrm{~N}$. Four days before sacrifice, rats in group 4 were placed one per cage, and underwent a $50 \%$ food restriction for $4 \mathrm{~d}$. The diet of food restricted rats was fortified with vitamin and mineral mixtures, to provide them as much micronutrients as unrestricted rats.

After $4 \mathrm{wk}$. on the diets, the rats received a BrdU injection $(50 \mathrm{mg} / \mathrm{kg}$, Sigma) $60 \mathrm{~min}$ before sacrifice by chloroform. The colons were fixed in buffered formalin, stained with methylene blue, blinded and scored for ACF using Bird's procedure $(7,8,9)$. Two-crypt ACF were then marked with ink under the microscope (x 40), putting the two aberrant crypts in line with, and between, two ink spots, and leaving exactly 5 normal crypts between each ink mark and the ACF. Blocks containing ACF were embedded in paraffin, and longitudinal sections of 3-4 $\mathrm{mm}$ were made, so that both aberrant crypts and both ink marks could be seen in the same section.

Stringent crypt scoring criteria were followed (1), and aberrant crypts were selected "blindly" on slides, only based on their position between ink marks. The crypt height and the proliferation were assessed, in both normal and aberrant crypts, after immuno-staining for BrdU (antibodies and biotin-extravidin-DAB from
Sigma) and hematoxylin counterstain (14). The number of apoptotic bodies was assessed based on histological features (5), after Feulgen fastgreen staining (22). Scoring was made blindly in duplicate, by 2 independent observers.

A three-way ANOVA was used to determine the effect of observer, diet, and crypt type on the number of cells per half-crypt, BrdUlabeled cells per crypt and per 100 cells (Labeling Index, LI), mitotic figures per crypt and per 1000 cells, proliferative zone (estimated by the position of highest labeled cell) and percent of crypt height, apoptotic figures per crypt and per 1000 cells, and micronuclei per crypt and per 1000 cells. The mean for all crypts evaluated in one rat (12 aberrant and 40 normal crypts per rat) was used in the ANOVA, giving $\mathrm{n}=6$ rats per group $(9)$.

\section{Results}

Food intake, water intake, and body weight (mean $241 \mathrm{~g} / \mathrm{rat}$ ) were not different between groups (except for restricted rats, given $10 \mathrm{~g}$ of food for 4 days instead of the average 20 $\mathrm{g} / \mathrm{d}$ spontaneous intake). Rats in group 2 ingested $150 \mathrm{mg} / \mathrm{kg} / \mathrm{d}$ cholic acid, and rats in group 3 ingested $2.7 \mathrm{~g} / \mathrm{kg} / \mathrm{d}$ Na phytate. ACF number and multiplicity were not designed endpoints of the study, since a $30 \mathrm{~d}$ feeding period, and a number of 6 rats per group, may not be enough to detect promotion or protection. A mean number of 66 ACF was detected per colon, their multiplicity was 2.0 crypts/ACF (no significant difference between groups, $\mathrm{p}=0.5$ and 0.4 ). The lowest number of ACF was detected in cholate fed rats (56/colon vs 66 in controls), and the smallest ACF multiplicity in phytate fed rats (1.9 crypt/ACF vs 2.1 in controls).

A total of 300 aberrant crypts, and 900 normal crypts, were scored for proliferation and apopotosis. The main results are given in the table (only part of data is shown).

Aberrant crypts, compared to normal crypts, were higher $(+17 \%$ cells, $\mathrm{p}<0.001)$, proliferated more (doubled labeling index, $\mathrm{p}<0.001$; doubled mitotic figures per crypt, $\mathrm{p}<0.001$, data not shown). The proliferative zone was shifted in 
Table 1: Effect of dietary cholate, phytate, and food restriction proliferation and apoptosis index in normal and aberrant crypts.

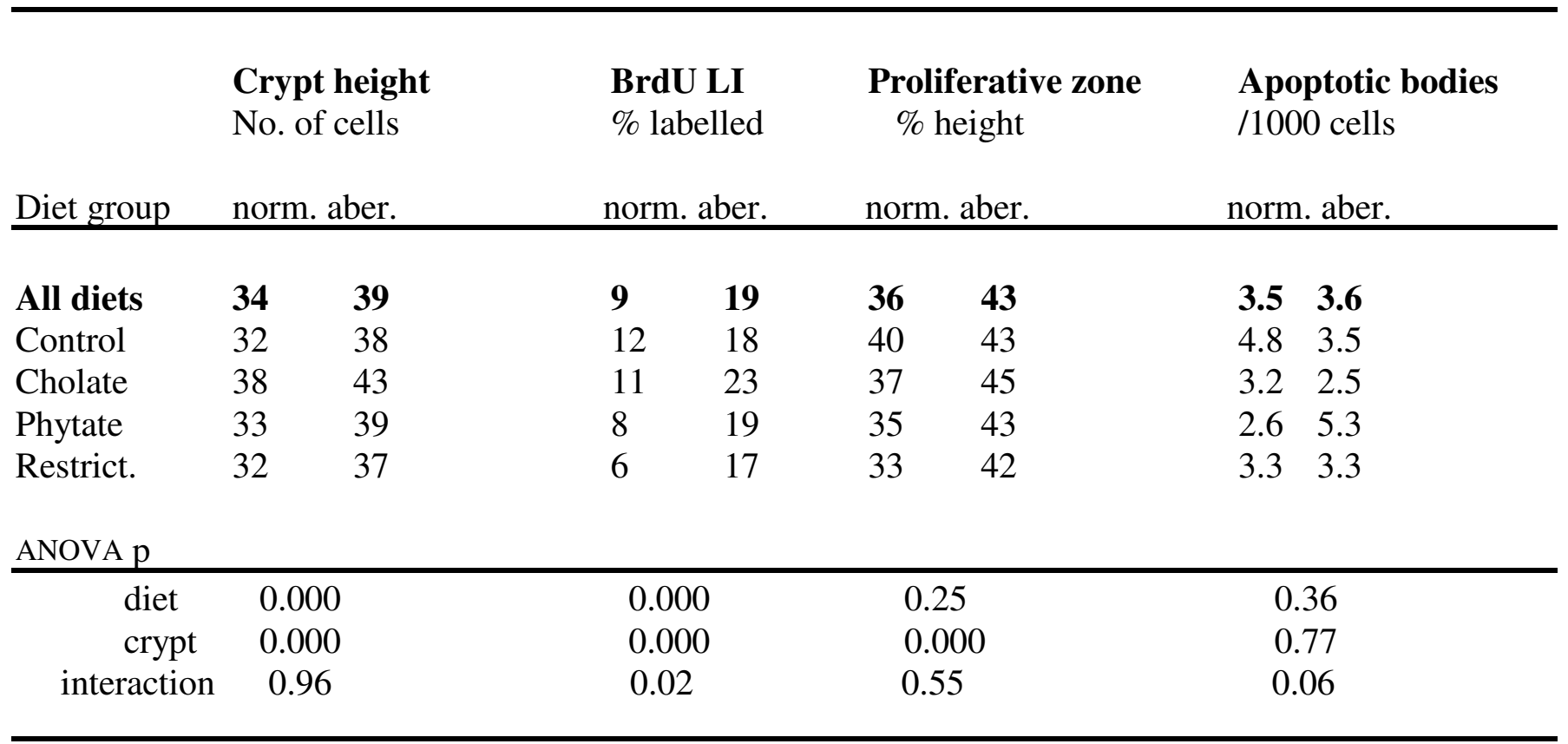

Crypt type : norm., normal, aber., aberrant ; LI, Labeling index ; Restrict., 50\% food restriction ;

decimal data and SD not shown to keep table simple to read, but full data included into the ANOVA analysis.

ACF toward lumen $(\mathrm{p}<0.001)$. The significant $\mathrm{p}$ value for the (diet $\mathrm{x}$ crypt) interaction (see the table last row) suggests that diets had differential effects on normal and aberrant crypts, which is the basis for a selecting effect.

Cholate, compared to control diet, increased the crypt height $(+15 \%, \mathrm{p}=0.001)$ of all crypts, and the proliferation of aberrant crypts $(+30 \%, \mathrm{p}=$ $0.03)$, but not of normal crypts $(-15 \%, \mathrm{p}=0.46)$.

Phytate, compared to control diet, decreased the proliferation of normal crypts $(-40 \%, \mathrm{p}=0.001)$, but not of aberrant crypts $(+2 \%, p=0.99)$.

Food restriction, compared to control diet, decreased the proliferation of normal crypts ($50 \%, \mathrm{p}<0.001)$, but not of aberrant crypts $(-7 \%$, $\mathrm{p}=0.82)$. Apoptosis was not different in normal and aberrant crypts, and was not affected by diets, but a marginally significant increase in ACF of rats given phytate $(p=0.08)$ : the (aberrant/normal crypt) ratio for apoptosis was 0.74 in rats fed control diet, and 2.0 in rats given phytate ( $\mathrm{p}$ for interaction 0.06 ).

\section{Discussion}

Results support the hypothesis that a tumor promoter, cholate, can select aberrant crypts by specifically stimulating their growth without enhancing the proliferation of normal crypts. This "selection" hypothesis was also weakly supported by a published study (9). Chronic feeding of cholic acid results in the development of increased resistance to apoptosis induced by azoxymethane. However, the effect is similar in both normal and aberrant crypts, without any (diet x crypt) interaction (9). Present data show no significant difference in apoptosis between rat groups or crypt types, likely because the "spontaneous" apoptosis rate is much smaller than the azoxymethane induced rate. It is also possible that our apoptosis assessment was biased, and confirmation would require specific labeling. Bile acids increase the proliferation of "normal" colonic mucosa in some studies (13, 16), but not in the present study and others (9). ACF detected in the colon of rats or humans have an increased proliferative activity compared to normal crypts, as in the present study $(9,10$, $14,17,23)$. 
In contrast with cholate data, food restriction and phytate proliferation data do not support the hypothesis that dietary protectors "counterselect": both diets decreased the cell proliferation in normal crypts but not in ACF. If the "selection model" was true, this would benefit to the ACF growth, and those "protectors" would be "promoters". However, phytate seemed to specifically increase apoptosis in ACF, which could counterselect. In the liver, a severe food restriction lowers cell replication and preferentially enhances apoptosis of preneoplastic liver cells (3). In the colon, food restriction increases the incidence of dimethylhydrazine induced apoptosis (4), but here it did not change the "spontaneous" apoptosis rate. Caloric restriction decreases cell proliferation in rat and human colon $(2,7,19)$. Similarly, dietary phytate decreases colonic epithelial cell proliferation $(13,20,21)$. Present results also show that phytate and food restriction decrease proliferation in normal crypts, but not in ACF. An alternative to our "selection" hypothesis is that tumor protector would curb the initiated stem cells at the base of the crypt. This would decrease the probability that an ACF arises and/or that an aberrant crypt branches, leading to less or smaller ACF, and eventually less cancer.

Acknowledgement: This work was supported by a grant from the DGER "Ministère de l'Agriculture", France.

\section{References}

1. Cameron, I. L., Beer, W.L., Lang, K.L., Kadiaka, S.C., Speeg, K.V. and Hardman, W. E. (1995) Predicting stages of human colon tumorigenesis from analysis of proliferating cell nuclear antigen (PCNA) stained rectal mucosa. Proc. Amer. Assoc. Cancer Res. 36: \#784.

2. Fleming, S. E., Youngman, L. D. and Ames, B. N. (1994) Intestinal cell proliferation is influenced by intakes of protein and energy, aflatoxin, and whole-body radiation. Nutrition and Cancer 22: 11-30.

3. Grasl-Kraupp, B., Bursch, W., Ruttkay-Nedecky, B., Wagner, A., Lauer, B. and Schulte-Hermann, R. (1994) Food restriction eliminates preneoplastic cells through apoptosis and antagonizes carcinogenesis in rat liver. Proc. Natl. Acad. Sci. USA. 91: 9995-9999.

4. Ishizuka, S., Sonoyama, K. and Niki, R. (1994) Food deprivation increases apoptotic cell counts induced by 1,2-dimethylhydrazine in rat descending colonic and rectal crypts. J. Nutr. Sci. Vitamin. 40: 363-369.

5. Kerr, J. F. R., Winterford, C. M. and Harmon, B. V. (1994) Apoptosis Its significance in cancer and cancer therapy. Cancer. 73: 2013-2026.

6. Kumar, SP, Roy SJ, Tokumo K, Reddy BS. (1990) Effect of different levels of caloric restriction on azoxymethane induced colon carcinogenesis in male F344 rats. Cancer res. 50:5761-5766:

7. Lasko, C. M. and Bird, R. P. (1995) Modulation of aberrant crypt foci by dietary fat and caloric restriction: the effect of delayed intervention. Cancer Epidemiology Biomarkers \& Prevention. 4: 49-55.

8. Magnuson, B. A., Carr, I. and Bird, R. P. (1993) Ability of aberrant crypt foci characteristics to predict colonic tumor incidence in rats fed cholic acid. Cancer Research. 53: 4499-4504.

9. Magnuson, B. A., Shirtliff, N. and Bird, R. P. (1994) Resistance of aberrant crypt foci to apoptosis induced by azoxymethane in rats chronically fed cholic acid. Carcinogenesis. 15: 1459-1462.

10. McLellan, E. A., Medline, A. and Bird, R. P. (1991) Dose Response and Proliferative Characteristics of Aberrant Crypt Foci - Putative Preneoplastic Lesions in Rat Colon. Carcinogenesis. 12: 2093-2098.

11. McSherry, C. K., Cohen, B. I., Bokkenheuser, V.D., Mosbach, E.H., Winter, J., Matoba, N. and Scholes, J. (1989) Effect of calcium and bile acid feeding on colon tumors in the rat. Cancer Research. 49: 6039-6043.

12. Nagengast, F. M., Grubben, M. J. A.L. and Vanmunster, I. P. (1995) Role of bile acids in colorectal carcinogenesis. European Journal of Cancer. 31A: 1067-1070.

13. Nielsen, B. K., Thompson, L. U. and Bird, R. P. (1987) Effect of phytic acid on colonic epithelial cell proliferation. Cancer Letters. 37: 317-325.

14. Pretlow, T. P., Cheyer, C. and Oriordan, M. A. (1994) Aberrant crypt foci and colon tumors in f344 rats have similar increases in proliferative activity. International Journal of Cancer. 56: 599-602.

15. Pretlow, T.P., Oriordan, M.A., Somich, G.A., Amini, S.B. and Pretlow, T.G. (1992) Aberrant crypts corre-late with tumor incidence in rats 
treated with azoxymethane and phytate.

Carcinogenesis. 13: 1509 -1512.

16. Robblee NM, McLellan EA, Bird RP. (1989)

Measurement of the proliferative status of colonic epithelium as a risk marker for colon carcinogenesis: effect of bile acid and dietary fiber.

Nutr Cancer. 12:301_310:

17. Roncucci, L., Pedroni, M., Fante, R., Digregorio, C. and Deleon, M. P. (1993) Cell kinetic evaluation of human colonic aberrant crypts. Cancer Research. 53: 3726-3729.

18. Shamsuddin, A. M. (1995) Inositol phosphates have novel anticancer function. J. Nutr. 125: 725S-732S.

19. Steinbach, G., Kumar, S. P., Reddy, B. S., Lipkin, M. and Holt, P. R. (1993) Effects of caloric restriction and dietary fat on epithelial cell proliferation in rat colon. Cancer Research. 53: 2745-2749.

20. Thompson, L. U. and Zhang, L. (1991) Phytic Acid and Minerals - Effect on Early Markers of Risk for Mammary and Colon Carcinogenesis. Carcinogenesis. 12: 2041-2045.

21. Ullah A, Shamsuddin AM. (1990) Dose dependent inhibition of large intestinal cancer by inositol hexaphosphate in F344 rats. Carcinogenesis. 11: 2219-2222.

22. Wargovich MJ, Goldberg MT, Newmark HL, Bruce WR. (1983) Nuclear aberrations as a short-term test for genotoxicity to the colon : evaluation of nineteen agents in mice. JNCI. 71: 133-137:

23. Yamashita, N., Minamoto, T., Onda, M. and Esumi, H. (1994) Increased cell proliferation of azoxymethane-induced aberrant crypt foci of rat colon. Japanese Journal of Cancer Research. 85: 692-698. 